\title{
Resenha do livro Técnicos, Intelectuais e Políticos na Nova República: um perfil dos dirigentes públicos dos governos Fernando Henrique, Lula e Dilma \\ Juliana Mochel e Gustavo Azevedo
}

Juliana Sousa de Araújo Mochel

Mestre em Ciência Política na Universidade Federal Fluminense (UFF) e doutoranda em Ciências Sociais na PUC Rio.

Email: juliana_mochel@hotmail.com

ORCID: https://orcid.org/0000-0003-2531-4842

\section{Gustavo Cravo de Azevedo}

Doutorando, mestre, licenciado e bacharel em Ciências Sociais pela Pontifícia Universidade Católica do Rio de Janeiro.

Email: gustavo_cravo@hotmail.com

ORCID: https://orcid.org/0000-0003-2743-3503

O livro apresenta dados sobre a qualificação profissional do alto funcionalismo público federal após extensa pesquisa empírica realizada. Através do levantamento de dados de pessoas que ocuparam cargos de Direção e Assessoramento (DAS), nos níveis 5 e 6, incluindo também os de Natureza Especial (os mais altos cargos nessa seara), entre os anos de 1995 e 2012. A professora Maria Celina D'Araujo, vinculada a Pontifícia Universidade Católica do Rio de Janeiro, e os demais autores do livro, jogam luz em um aspecto ainda pouco explorado da Administração Pública Federal: o perfil dos dirigentes públicos que ocupam os mais altos cargos da administração federal. A pesquisa, que teve duração superior a 17 anos e atravessou diversos períodos presidenciais, compilou dados de mais de 1000 pessoas. Trata-se de grupo de pessoas bem posicionadas na tomada de decisões sobre políticas públicas.

Ao se debruçar sobre o alto escalão da administração pública federal e reunir robusta base de dados biográficos, o trabalho realizado pelos autores permite conhecer de fato quem compõe essa elite estatal, perpassando seus aspectos profissionais, educacionais, demonstrando também se esses indivíduos são ou não são associados a partidos políticos e/ou sindicatos.

De modo geral, tal segmento da administração pública costuma ser muito criticado e constantemente posto em xeque quanto à sua qualidade, tecnicidade e aos critérios que levaram à sua escolha. Um dos méritos do trabalho consiste não só em apresentar em detalhes essa elite burocrática, mas também em desmitificar certas premissas tão comumente associadas ao alto funcionalismo público.

Uma das conclusões que mais chamam atenção é que a profissionalização, a educação formal e a experiência pautam o perfil dessas indicações. Os autores levantaram dados sobre o universo pesquisado e afirmam que $24 \%$ dos dirigentes possuem o título de doutor e, na outra ponta, 19,2\% o título de graduação. A pesquisa, portanto, garante que a elite burocrática também se trata da elite intelectual. 
A obra conta com uma introdução e está dividida em cinco capítulos. Todos possuem como fonte a extensa pesquisa e organização de dados sobre altos dirigentes da administração pública federal. Apresenta-se abaixo, em síntese, o que é abordado em cada um dos capítulos.

O cerne do primeiro capítulo é demonstrar, através de dados empíricos, se após a redemocratização manteve-se o mesmo padrão "diferenciado no recrutamento e no perfil dos dirigentes públicos nos Ministérios da Fazenda e Planejamento, ditos econômicos, e nos da Saúde e da Educação, representando a área social (D'ARAújo; PETEK, 2018, p. 37)." Além disso, investiga se houve ou não diferenças nos três governos. Para tanto, utilizou-se como critérios o recrutamento regional; os vínculos profissionais do dirigente com os setores públicos e privados; a escolaridade dos dirigentes e de seus pais; a filiação partidária; os vínculos com sindicatos; e a relação com os movimentos sociais.

No que tange ao recrutamento regional, há um predomínio da região Sudeste tanto na área econômica quanto na social, embora seja pertinente destacar também a participação do Centro Oeste, principalmente nos governos Fernando Henrique Cardoso, e Dilma Roussseff. A relevância dessa região, se dá, principalmente, por conta da capital federal, Brasília, que aumentou sua participação nessa parcela da administração, indicando crescente recrutamento dentro da própria burocracia federal. Destaca-se que esse fenômeno precisa ser mais estudado. i

Em relação à vinculação dos dirigentes com os setores público e privado, cerca de $20 \%$ dos nomeados para cargos de DAS níveis 5 e 6 e de Natureza Especial advém do próprio órgão do serviço público federal, no qual passaram a atuar em cargo de confiança.

Nos ministérios da área econômica, observa-se que à exceção do governo Luiz Inácio Lula da Silva, que priorizou o recrutamento no interior dos próprios órgãos, os governos Fernando Henrique Cardoso e Dilma Rousseff apresentaram uma distribuição mais equitativa entre os padrões de recrutamento funcional. Já nos ministérios da área social, evidencia-se o predomínio do recrutamento de servidores requisitados de outros órgãos e/ou esferas. Nota-se que no governo Fernando Henrique Cardoso pouco mais de $60 \%$ enquadravam-se nessa categoria, nos anos Lula, esse patamar foi de $50 \%$, e no durante o primeiro mandato da presidente Dilma, essa categoria chegou a quase $70 \%$.

Quanto à escolaridade dos dirigentes, o trabalho comprova que, ao contrário do que prega boa parte da literatura sobre o Brasil, os ministérios da esfera econômica não são os mais escolarizados. Segundo os dados da pesquisa, com algumas pequenas diferenças percentuais entre um nível de escolaridade e outro, nos três governos estudados, foram os dirigentes da área social que apresentaram maior escolaridade. Nos anos FHC, por exemplo, $100 \%$ dos altos burocratas dos Ministério da Educação e da Saúde são pós-graduados, enquanto nos Ministério da Fazenda e do Planejamento, aproximadamente, um quarto têm apenas nível superior.

Relativamente à filiação partidária, aponta-se que comparado aos demais ministérios, a Fazenda é aquele que detém o menor número de filiados, indicando que as nomeações nessa área têm um caráter mais técnico. No tocante a quais partidos os dirigentes desses quatro ministérios eram filiados, atenta-se para os números dos governos Lula e Dilma, ambos vinculados ao Partidos dos trabalhadores (PT), em que 
dentre os filiados a partidos políticos, aproximadamente $80 \%$ eram também do PT. No que diz respeito à filiação sindicali", as áreas econômicas apresentaram um menor número de dirigentes sindicalistas nos três governos. Sobre esta temática, o estudo chama atenção para os dados referentes aos dois governos Lula, no qual a presença sindical entre os dirigentes foi sem dúvida, mais marcante, chegando a atingir patamares entre $45,3 \%$ no primeiro mandato, e $36,1 \%$ no segundo, enquanto no governo FHC observou-se apenas $21,3 \%$ e no governo Dilma Rousseff, $21 \%$.

Já em relação aos movimentos sociais, apesar de estarem historicamente ligados ao PT, sua presença entre os dirigentes em ambas as áreas ficou bem mais evidente nos anos Lula, chegando a haver um declínio dessa participação ao longo do governo Dilma Rousseff.

Por fim, a pesquisa aborda questões cada vez mais recorrentes na literatura, que são gênero e etnia. De acordo com os resultados obtidos, desde a redemocratização, ainda é possível verificar a grande ausência de mulheres e afrodescendentes nos altos cargos da administração pública brasileira, embora aponte uma melhora nesses indicadores. Se no governo Fernando Henrique a participação feminina nos cargos de DAS 5 e 6 e de Natureza Especial era de 15,6\%, no governo Dilma esse patamar foi de $31,3 \%$.

Essa tendência de crescimento foi igualmente observada entre os que se declaram negros e pardos, sendo $8,4 \%$ nos anos $\mathrm{FHC} ; 10,8 \%$ no primeiro mandato de Lula e 15,5\% no segundo; e 18,5 no governo Dilma Rousseff.

Na linha dessa temática, o segundo capítulo versa sobre o perfil das mulheres dirigentes públicas, demonstrando sua evolução ao longo do período estudado. Ainda que a desigualdade de gênero se mantenha, a administração pública se mostrou um campo em que as mulheres, verifica-se um aumento do número de mulheres nos governos Lula e Dilma Rousseff, num contexto em que, para além da linha ideológica partidária, a atuação dos movimentos sociais e as pressões internacionais foram fundamentais.

Observa-se que ao se comparar as diferentes áreas a distribuição das mulheres nos cargos não é paritária, e isso varia também de governo a governo, por exemplo: na área econômica, no governo Fernando Henrique, as dirigentes ocupavam $41,6 \%$ dos cargos; no governo Lula da Silva, $11,7 \%$ e no governo Dilma Rousseff, $13, \%$. Já nos cargos vinculados à Presidência da República, nos anos FHC não havia mulheres dirigentes, ao passo que no governo Lula se tinha $18,9 \%$, e no primeiro mandato do governo Dilma, $15,9 \%$.

No que se refere à etnia, continua o predomínio de mulheres brancas. No entanto, um dos pontos mais interessantes da pesquisa foi a descoberta de que gradualmente essa proporção se reduz $18,3 \%$, com uma velocidade acima daquele observada na amostra como um todo. Os dados coletados ao longo da pesquisa demonstram que a etnia das mulheres dirigentes distribuía-se do seguinte modo: a) Governo FHC: $0 \%$ preta; 5,4\% pardas; $92 \%$ brancas; e 2,7\% amarela.; b) Governo Lula:2,2\% pretas; $14,6 \%$ pardas; $79,7 \%$ brancas; 3,2\% amarela; c) Governo Dilma: $5,7 \%$ pretas; $17 \%$ pardas; $73,7 \%$ brancas; amarela $3,4 \%$.

Em relação ao engajamento social, carreiras e políticas, percebe-se que o nível de associativismo, entendido como o nível de participação em movimentos sociais, sindicatos, associações e demais formas associativas, entre as dirigentes é alto ainda 
que menor se comparado aos homens. Os dados referentes à essa questão sugerem que há uma alta participação de mulheres filiadas à sindicados $(39,7 \%)$ e participantes de movimentos sociais $(59,5 \%)$ nos governos petistas.

Quanto à filiação partidária, os autores afirmam que:

$$
\begin{aligned}
& \text { Grande parte das dirigentes públicas, assim como dos } \\
& \text { homens na mesma posição, não é filiada a partidos } \\
& \text { políticos (menos de um quarto), o que indica que a } \\
& \text { carreira político-partidária não faz parte da maioria delas. } \\
& \text { No entanto, quando são filiadas, integram, em geral, o } \\
& \text { partido do presidente em exercício. A filiação, por sua } \\
& \text { vez, é alta entre as dirigentes recrutadas fora do serviço } \\
& \text { público. (D'ARAÚJO; MACEDO; 2018, p. 70) }
\end{aligned}
$$

Ao se debruçar sobre a escolaridade das mulheres dirigentes, os dados compilados pelas autoras em relação "ao nível educacional, às instituições nas quais fizeram sua qualificação e aos cursos que frequentaram" (D'ARAÚJO; MACEDO; 2018, p. 72) permitem concluir que se trata de um grupo altamente escolarizado, uma vez que $78,4 \%$ das mulheres possuem algum tipo de pós-graduação. As autoras pontuam que $o$ aumento do grau de titulação está relacionado à exigência dessa credencial para aprovação em concurso público. Além disso, reforçam que as ocupantes desses cargos são altamente qualificadas, e que, portanto, as relações pessoais e políticas, podem até interferir, mas o fator preponderante é a capacitação (D'ARAÚJO; MACEDO; 2018, p. 72)

Ainda sobre a discussão da escolaridade, o capítulo três traz à baila pertinentes informações sobre a formação acadêmica dos altos dirigentes brasileiros, entendidos como uma "nobreza de Estado", nos termos de Pierre Bourdieu, uma vez que se caracterizam pelos altos níveis de escolaridade e de especialização técnica, além do alto grau de comprometimento com o aparato burocrático estatal.

A partir dos dados coletados, nota-se que dentre os dirigentes públicos, quase todos são graduados e cerca de $78 \%$ possuem pós-graduação. Esses dados mostram a disparidade com a realidade da sociedade brasileira, que possui grau de instrução ainda muito baixo. Os autores afirmam que pelos dados da Organização para Cooperação e Desenvolvimento Econômico (OCDE), em 2017, somente 15\% da população adulta entre 25 e 64 anos conseguiram terminar o ensino superior no Brasil (D'ARAÚJO; PETEK; RIBEIRO, 2018). Além disso, os dados da Pesquisa Nacional por Amostra de Domicílios Contínua (PNAD) de 2018 aponta que mais de 50\% dos brasileiros com 25 anos ou mais não concluiu a educação básica: $33,1 \%$, não completou nem o ensino fundamental, enquanto 6,9\% não possuem instrução alguma, $8,1 \%$ concluiu o fundamental completo e $4,5 \%$ terminaram o ensino médio incompleto. Isso evidencia que a administração pública é altamente seletiva, formando não só uma elite social, como também uma elite econômica. iii

Após constatar o avanço que as Ciências Sociais tiveram ao longo dos anos pesquisados, entende-se como ponto central deste capítulo a elaboração de um panorama do perfil dos cientistas sociais na alta administração pública. Atesta-se que, considerando mestrado e doutorado, Ciências Sociais aparece em segundo lugar na proporção de maiores titulações, perdendo apenas para Medicina. Corroborando com o estereótipo de militância política tão atrelada aos cientistas sociais, observa-se que se 
trata da categoria profissional, mais vinculada a partidos políticos, ao passo que são os menos governistas.

Por oferecer uma formação "genérica", o curso de Ciências Sociais forma profissionais capazes de atuar em diversas áreas, uma vez que constituem um grupo difuso, sem uma identidade coletiva e única no mercado de trabalho (BRAGA, 2018). .v

Conforme evidenciado na pesquisa, os cientistas sociais não se concentram em um setor específico, estando mais representados nos campos Ciências, Educação, Cultura e Lazer. Além disso, salienta-se seu ethos acadêmico e a vocação para docência. Isto posto, considerando a estrutura da alta administração pública associada à complexidade dos problemas brasileiros, os cientistas sociais têm um importante papel na criação de novas categorias de conhecimento e na transformação da teoria em uma prática capaz de fazer a diferença positivamente. Nesse sentido, características como capital intelectual próprio e rigor analítico, ajudaram a colocar as Ciências Sociais no rol das profissões que compõem essa "nobreza de Estado".

O quarto capítulo irá observar dados sobre escolaridade, experiência na administração pública, filiação sindical, filiação partidária e associativismo consideradas atividades em conselhos profissionais e/ou movimentos sociais - entre os dirigentes, que recebem DAS 5 e 6, e também $\mathrm{NE}$, que ocupam cargos: (1) na área de desenvolvimento; (2) na área social; (3) na Presidência da República. Foram recolhidos dados de 649 dirigentes destas três áreas. Em comum, as duas primeiras áreas são áreas produtoras de políticas públicas. Os dados apresentados nesse capítulo confirmam um perfil altamente experiente no conjunto das três áreas. Em comum entre as áreas, está também que, entre os servidores, a maior parte provém do serviço público (servidor efetivo do órgão ou servidor requisitado de outro órgão e/ou esfera): $64,3 \%$ na área de desenvolvimento, $66,8 \%$ na área social, e 50,4\% na Presidência da República.

A escolha das áreas se deu diferentes razões. D'Araujo e Mendes (2018, p. 101 e 102) explica que a Presidência é um espaço privilegiado para a articulação política e é o principal centro de poder em sistemas presidencialistas. Sendo assim, um dos objetivos do capítulo é observar se o recrutamento para a Presidência dispõe de alguma peculiaridade em relação aos demais dirigentes políticos. Além disso, há escassez de literatura sobre o perfil de quem assessora os ministros nas áreas de desenvolvimento e social. Soma-se aos fatores que influenciaram a escolha das áreas a importância das atribuições desses órgãos para a democracia brasileira. Os sociais foram alçados à condição de peças centrais da República com a Constituição de 1988. Os ministérios de desenvolvimento são cruciais para a superação de gargalos estruturais da economia. A Presidência é uma área que, a princípio, não exigiria demanda por formações particulares, visto que não produz políticas públicas que exijam um conhecimento específico. Apesar de não produzir nenhuma política pública específica, a Presidência tem funções de elevada complexidade.

A conclusão é que existem diferenças significativas entre as áreas de Desenvolvimento, Social e Presidência da República. Todos possuem elevada escolarização, no entanto, esta elevada escolarização não se apresenta de forma homogênea entre as áreas. De acordo com os autores:

(...) quase $100 \%$ dos pesquisados, nas três áreas, têm pelo menos nível superior completo, e a maioria concluiu pelo menos um curso de pós-graduação. As duas áreas 
de políticas públicas são as que apresentam maior qualificação: $62,2 \%$ dos dirigentes da área social e $44,9 \%$ da de desenvolvimento concluíram mestrado ou doutorado, contra 38,8\% da Presidência da República. Essa área é aquela com maior número de dirigentes que concluíram somente o nível superior (28,4\%). Além disso, as áreas de desenvolvimento e social, embora apresentem grande quantidade de pós-graduados, mostram um perfil distinto: os primeiros apresentam um maior número de especializações, cursos lato sensu geralmente mais voltados para o mercado de trabalho, enquanto a área social mostra preferência pela pósgraduação strictu sensu, indicando um traço mais acadêmico. (D'ARAÚJO; MENDES, 2018, p. 108)

O quinto capítulo reúne informações detalhadas sobre a maior parte dos ministros do Brasil que ocuparam o cargo por, pelo menos, três meses a partir do governo de 1985 até 2014, atravessando os governos de José Sarney, Fernando Collor, Fernando Henrique Cardoso, Luiz Inácio Lula da Silva e parte do segundo mandato de Dilma Rousseff. Reúne dados biográficos detalhados de 406 ministros que ocuparam o poder no período.

O Brasil é um país presidencialista e o arranjo político é conhecido como presidencialismo de coalizão. D'Araujo e Ribeiro (2018, p. 125) afirmam que "os ministros são estratégicos uma vez que ajudam na definição de políticas públicas, autorizam despesas do Executivo, amortecem conflitos políticos e são exemplos da pluralidade e da repartição de poder". Devido à sua alta posição e suas atribuições, o perfil dos ministros, bem como os padrões de recrutamento e suas carreiras políticas continuam a merecer atenção especial. Entre as justificativas para o capítulo, está que o padrão de nomeação dos ministros no Brasil ainda não foi suficientemente estudado. Importante ressaltar que os dirigentes ocupantes de cargos DAS 5 e 6 e também de cargos $\mathrm{NE}$, uma elite burocrática e intelectual, conforme aponta o texto, encontram-se abaixo hierarquicamente dos ministros.

A tese apresentada neste capítulo, de que à exceção da área econômica, as nomeações dos ministros brasileiros são frutos de arranjos político-partidários e regionais, que na maioria das vezes, não obedece à critérios técnicos, corrobora a versão endossada pela tese do presidencialismo de coalizão.

No período abordado no quinto capítulo, isto é, de 1985 a 2014, aproximadamente metade dos ministros brasileiros, num total de 406 estudados, teve experiência parlamentar ou foi recrutado no parlamento. A grande maioria, 387 dos pesquisados, teve cargos executivos (prefeito, governador, secretários ou ministro), sendo poucos os inexperientes na vida pública. No entanto, ressalta-se que essa inexperiência não é sinônimo de competências técnicas para atuar no cargo para o qual foram nomeados.

O presidencialismo brasileiro ainda é marcado por intensa partidarização dos gabinetes ministeriais, sempre observando o apoio de cada partido no Legislativo ao partido que ocupa a Presidência. Nos exemplos observados no livro, vale dizer que desde a assim chamada Nova República, ou seja, desde 1985, "a correlação entre o tamanho das bancadas no Congresso e a participação dos partidos no gabinete foi mantida até a chegada do PT ao poder em 2003" (D'ARAUJO e RIBEIRO, 2018, p. 
128). Houve visível sobrerrepresentação do próprio PT dentre as indicações para ministérios. O livro aponta que esse desequilíbrio na distribuição proporcional das pastas ministeriais entre o PT e os demais partidos que compunham sua base resultaram em tensão política.

Outros dados interessantes são que há grande concentração dos ministros avindos da região Sudeste. Em todos os governos, de Sarney a Dilma Rousseff, a maioria dos ministros era provenientes dessa região, representando $52,6 \%$ do total. ${ }^{v}$

Dito de maneira mais direta, a desigualdade regional do país fica clara na distribuição desigual do poder, pois enquanto a Sudeste concentra mais da metade dos ministros, a região Norte representa apenas 3,9\%.

Há também desigual distribuição de poder sob outros pontos de vista já que minorias étnicas estão longe de ser representadas nos ministérios, representando apenas $16,8 \%$ do total pesquisado e que o número de mulheres indicadas vem aumentando, porém, de maneira lenta: nos governos Sarney e Fernando Henrique a presença feminina na composição dos ministérios é praticamente inexistente, já no governo Dilma Rousseff atingiu seu maior participação, com 17,8\% (13 ministras) do total.

(Recebido para publicação em agosto de 2019)

(Reapresentado em outubro de 2019)

(Aprovado para publicação em dezembro de 2019)

\section{Cite esta resenha}

MOCHEL, Juliana e AZEVEDO, Gustavo, 2019. Resenha do Livro Técnicos, Intelectuais e Políticos na Nova República: um perfil dos dirigentes públicos dos governos Fernando Henrique, Lula e Dilma de Carla Michele Rech. Revista Estudos Políticos: a publicação semestral do Laboratório de Estudos Hum(e)anos (UFF). Rio de Janeiro, Vol.10 |N.2, pp. 266- 273, dezembro de 2019.

\section{Notas}

1. No governo FHC, $40,8 \%$ dos dirigentes públicos procediam da região Sudeste; $39,1 \%$ do CentroOeste; $8 \%$ do Nordeste; $7,1 \%$ do Sul; $4,6 \%$ do exterior; e $0,4 \%$ do Norte. No primeiro mandato do governo Lula, os dados apontam que: $52,6 \%$ do alto escalão da administração pública federal advém do Sudeste; $17,6 \%$ do Sul, $11,1 \%$ do Centro-Oeste, $11,1 \%$ do Nordeste; $4,7 \%$ do Norte; e 2,9\% do exterior. Já no seu segundo mandato, não há mudanças tectônicas em relação aos dados: $55,4 \%$ dos dirigentes são 
Juliana Mochel e Gustavo Azevedo

procedentes da região Sudeste; $16,9 \%$ do Sul; $13 \%$ do Nordeste; $10,9 \%$ do Centro-Oeste; $3,3 \%$ do Norte; e $0,5 \%$ do exterior. Por fim, no governo Dilma Rousseff tem-se que $51,3 \%$ advém do Centro-Oeste; $27,4 \%$ do Sudeste; $9,3 \%$ do Nordeste; $8,5 \%$ do Sul; $2,1 \%$ do exterior; e $1,4 \%$ do Norte.

2. A pesquisa não aborda quais são os sindicatos ou centrais sindicais aos quais os dirigentes são filiados.https://g1.globo.com/educacao/noticia/2 019/06/19/mais-da-metade-dos-brasileiros-de25-anos-ou-mais-ainda-nao-concluiu-aeducacao-basica-aponta-ibge.ghtml

3. BRAGA, Eugênio Carlos Ferreira. Novos elementos para uma sociologia dos cientistas sociais: a situação ocupacional dos egressos. Rev. bras. Ci. Soc., São Paulo, v. 26, n. 76, p. 103-122, June 2011. Available from <http://www.scielo.br/scielo.php?script=sci_artt ext\&pid=S010269092011000200006\&lng=en\&nrm=iso $>$. access on $14 \quad$ mar. 2020. https://doi.org/10.1590/S010269092011000200006.

4. Percentagem de Ministros procedentes da região Sudeste (1985-2014): Sarney- 46,2\%; Collor$58,8 \%$; Itamar- 60,5\%; FHC 1- 54,1\%; FHC 260,8\%; Lula 1- 52,5\%; Lula 2- 56,8; Dilma Rousseff- $39,4 \%$. 